\title{
Weaning and dental health
}

\author{
BY R. D. HOLT \\ Eastman Dental Institute, 256 Gray's Inn Rd, London WCIX 8LD
}

Tooth development begins at a very early stage in life with the initial stages being seen at about $28 \mathrm{~d}$ in utero and mineralization of primary teeth beginning well before birth at about 14 weeks in utero. Mineralization of permanent teeth starts later, at or just after the time of birth. The first tooth, usually a lower primary incisor, erupts at about 6 months of age, a time when weaning should have begun. Eruption continues in the months following, with the primary dentition being complete on average by the age of 2.5 years (Lunt \& Law, $1974 a, b)$.

Nutrition in early life represents a major determinant of future health; diet at this time may also be seen as the foundation for a child's dental health.

The importance of weaning in dental health was recognized by the working group of the Committee On Medical Aspects of Food Policy (COMA) considering weaning and the weaning diet. The COMA report on weaning was published in 1994 (Department of Health, 1994). The aim of the present paper is to consider a number of the issues that may be identified from the report and from more recently published evidence.

It is well recognized that weaning may affect dental health through its influence on caries. More recently it has also been increasingly appreciated that foods and drinks at weaning carry a potential for erosion. For some children, weaning practices or the foods or drinks given may carry a particular risk to dental health; these may require special consideration. Health promotion strategies for oral health aim to encourage mothers to make a wise choice of items to be used at weaning. Labelling of products becomes critical if this is to be practicable in real life. Appropriate use of fluoride is the most effective means of preventing caries in young children. Those who live in areas with optimal water fluoride levels may gain the greatest benefit from birth onwards but children may also be exposed to fluoride in the form of fluoride supplements or fluoride toothpaste from a very early age.

\section{WEANING AND DENTAL CARIES}

Dental caries is particularly a disease of children. It may affect teeth from the time they first erupt into the mouth and although it is normally slow to do so, in a minority of children it progresses very rapidly to result in extensive destruction of the dentition. This is true for both permanent and primary teeth.

\section{Prevalence of dental caries in young children}

In the 1970 s, the prevalence of dental caries showed a marked decline in children in many developed countries. In the permanent dentition and in older children the decline continued through the $1980 \mathrm{~s}$, but in primary teeth and in younger age groups the decline has halted (Downer, 1994; O'Brien, 1994). There has also been evidence that it may have increased in some population groups (Pitts \& Palmer, 1994). In the dental survey which formed a part of a national survey of nutrition in 1.5-4.5-year-old children it was reported that in 1992-3 $4 \%$ of $1.5-2.5$-year-olds and $30 \%$ of those aged $3.5-4.5$ years already had some 
Table 1. The prevalence (\%) of caries in preschool children in Camden in 1980, 1986 and $1993-4$

\begin{tabular}{cccc}
\hline \hline Age (years) & 1980 & 1986 & $1993-4$ \\
\hline 2 & 11 & 15 & 11 \\
& $(n 137)$ & $(n 150)$ & $(n 123)$ \\
3 & 22 & 28 & 29 \\
& $(n 116)$ & $(n 132)$ & $(n 95)$ \\
\hline
\end{tabular}

Table 2. The prevalence (\%) of rampant caries in preschool children in Camden in 1980, 1986 and 1993-4

\begin{tabular}{cccc}
\hline \hline Age (years) & 1980 & 1986 & $1993-4$ \\
\hline 2 & 3 & 9 & 6 \\
& $(n 137)$ & $(n 150)$ & $(n 123)$ \\
3 & 4 & 10 & 14 \\
& $(n 116)$ & $(n 132)$ & $(n 95)$ \\
\hline \hline
\end{tabular}

experience of caries (Hinds \& Gregory, 1995). Changes in prevalence of caries in young children were seen in results from a series of surveys in Camden carried out from 1980 and summarized in Table 1 (Holt, 1990; Holt et al. 1996). These results have provided little evidence of significant change since the mid 1980s in this inner city area. Rampant caries (sometimes termed 'bottle caries' or 'nursing caries') represents a particularly severe and often rapidly progressing form of the disease. In this type of caries, lesions affect the smooth surfaces of upper incisor teeth. Rampant caries affects a relatively small proportion of children but its prevalence may have increased in recent years. A summary of findings in relation to rampant caries in Camden is shown in Table 2 (Holt, 1990; Holt et al. 1996).

The incidence of caries has become more polarized with time so that those children affected suffer more severely than in the past; from results in the survey of dental health in preschool children it may be estimated that $80 \%$ of the disease experience was found in approximately $8 \%$ of the children (Hinds \& Gregory, 1995). At least two factors are associated with higher risk. First, in common with many diseases, caries has been shown to be related to social class. Thus, children from lower social classes, or those from families on income support may be at particular risk of the disease (Hinds \& Gregory, 1995). Second, amongst differing ethnic groups, preschool children of Asian origin suffer higher levels of caries and of rampant caries. In Camden, children of Asian origin were shown to be significantly more likely to have either any caries or to have rampant caries; social class failed to show the same effect in multivariate analysis. Odds ratios were 3.57 and 3.30 for the presence of caries and of rampant caries respectively (Holt et al. 1996).

\section{Aetiology of caries}

Caries is a consequence of acid production by plaque bacteria. The acid is produced as a by-product of bacterial metabolism of dietary substrate, particularly sugars. Measurements of plaque $\mathrm{pH}$ show that after eating sucrose, $\mathrm{pH}$ rapidly falls to a level below that required for enamel demineralization. With time $\mathrm{pH}$ slowly reverts to a resting level. Changes in $\mathrm{pH}$ radically affect the ionic equilibrium present at the interface between enamel and plaque resulting in a situation where periods of demineralization alternate with 
remineralization. The mechanism is complex and influenced by a large number of factors. Demineralization is favoured by low $\mathrm{pH}$ at the plaque-enamel interface, an appropriate plaque flora and low salivary flow. Conversely, neutral $\mathrm{pH}$, the presence of fluoride in sufficient concentration and salivary factors, such as buffering capacity, may favour remineralization. Only when demineralization exceeds remineralization does caries progress. Although aspects of caries are not fully understood, the essential role of both diet and plaque has been clearly demonstrated (Kite et al. 1950; Orland et al. 1954).

Caries most often occurs in parts of the world where basic nutrition is adequate and the pre-eruptive influence of diet is usually thought to be small (Rugg-Gunn, 1993). Amongst dietary factors, sugars in the form of non-milk extrinsic (NME) sugars have been concluded to be much the most important determinant of caries (Department of Health, 1989). Evidence for the role of sugars has come from a wide variety of sources; the evidence has been extensively reviewed elsewhere (Rugg-Gunn, 1993). In the most recent edition of the Scientific Basis of Dental Health Education published by the Health Education Authority, sweeteners listed as having potential to cause caries included dextrose, invert sugar, glucose, lactose, maltose, hydrolysed starch and fructose as well as sucrose (Health Education Authority, 1996). Both the amount and frequency of intake may be important and because salivary flow is reduced during sleep, intake at bedtime or nap time may be especially harmful.

\section{The weaning diet and caries}

The effect of the weaning diet on caries may be regarded as primarily a direct one on the newly erupted susceptible tooth. However, diet at this time may also be an important indicator of diet (and dental health) later in childhood (Persson et al. 1985). An indication of this in the UK was given in a longitudinal study in which it was found that use of sugar in children at 8-10 years was significantly related to use of sweetened comforters during infancy (Silver, 1987).

Because of the risk to dental health, the COMA panel report Dietary Sugars and Human Disease (Department of Health, 1989), recommended that NME sugars should make up no more than about 10-11\% of energy intake, a recommendation endorsed for weaning infants in the report Weaning and the Weaning Diet (Department of Health, 1994). COMA recommended that for groups of children, the average intake of NME sugars should be limited to about $10 \%$ of total dietary energy intake (Department of Health, 1994). This level may be exceeded by a proportion of children soon after, if not at the time of, weaning; in a large survey reported by Mills \& Tyler (1992) it was found that in children aged 9-12 months of age, NME sugars, on average, formed $12 \%$ of energy intake. In the national nutrition survey (Gregory et al. 1995) 1.5-2.5-year-old children gained $17 \%$ of their total energy from NME sugars.

In weaning foods and drinks, NME sugars may include not only sugars added as such during preparation by the manufacturer or carer, but also sugars included in the form of fruit juices or fruit concentrates (Durward, 1991). For many infants, drinks are likely to be a major source of NME sugars. In the national nutrition survey (Gregory et al. 1995), beverages made up $39 \%$ of NME sugar intake. Sugar, preserves and confectionery made up $27 \%$ and cereals and cereal products $23 \%$.

Rampant caries has been consistently linked to the habit of giving sweet drinks in feeding bottles or miniature feeders or dummies dipped in a sweet agent such as honey or jam and used to pacify or comfort the child. In the most recent survey in Camden, just over half of those with rampant caries compared with approximately one-third of those 
Table 3. The use of sweetened comforters and rampant caries among preschool children in Camden in 1993-4

\begin{tabular}{ccc}
\hline \hline & With rampant caries & No rampant caries \\
\hline Used a sweet comforter & 16 & 141 \\
No sweet comforter used & 15 & 234 \\
\hline
\end{tabular}

without rampant caries, had been given a sweetened comforter bottle to take to bed (see Table 3). It is of note that although prevalence was greater in those using a comforter of this type, given at bedtime or naptime, rampant caries also affected a proportion of those who had not done so, indicating the importance of other causes (Holt et al. 1996). One may be the practice of giving drinks in feeding bottles during the daytime but after the age of weaning. This has been demonstrated in the past and was shown to be a significant risk factor in the same study (King et al. 1983; Holt et al. 1996).

Recommendations to prevent dental disease were recently re-emphasized by the Health Education Authority (1996). To prevent caries the first recommendation is to reduce the consumption and especially the frequency of sugar-containing food and drink. Whilst recommendations refer to all age-groups, this primary recommendation to prevent caries re-echoes the very clear guidelines offered in relation to the weaning diet. These include the recommendation that weaning foods should usually be free of, or very low in NME sugars. This guide needs to apply to family foods and those prepared in the home as well as to manufactured infant and baby foods and drinks. It must be accepted that items high in sugars play some part in the diet of most children but it is recommended that items such as these, which are not nutritionally necessary and which predispose to caries, should be regarded as 'occasional' and limited to main mealtimes.

In the case of drinks, it is recommended that drinks other than milk or water should form a minority of total drinks, should be confined to main mealtimes and should not be given in a feeding bottle, or at bedtime (Department of Health, 1994). It has also been specifically recommended that mothers should be warned about the danger of putting fruit juice or sugar-sweetened drinks into feeding bottles for the child to hold, especially in bed (Health Education Authority, 1996).

\section{WEANING AND DENTAL EROSION}

Erosion is the process whereby dental hard tissues are lost as a direct result of chemical action. Although erosion may affect the same children, it is distinct from caries which results from acid produced by plaque bacteria. Erosion is unrelated to plaque or to the presence of dietary sugars.

Typically, erosion affects smooth tooth surfaces resulting in loss of normal tooth morphology and leaving concave areas with smooth shiny margins. With progress, the process comes to involve dentine and pulp tissue (Nunn et al. 1996).

Erosion is seen in permanent teeth in adolescents and in older subjects, but it also affects primary teeth in young children. Because primary teeth are smaller and enamel thinner, erosion may progress more rapidly to involve deeper tooth structure. Although it may have escaped recognition in the past, the prevalence of erosion in children in this country has been measured in two recent studies (O'Brien, 1994; Hinds \& Gregory, 1995). In the survey of dental health which formed a part of the nutrition survey of 1.5-4.5-yearold children in UK, erosion of incisors was found to affect at least $3 \%$ of the youngest age- 
group, increasing to $13 \%$ of the oldest (Hinds \& Gregory, 1995). In the national survey of dental health in school-aged children in the UK, erosion extending into dentine or pulp was diagnosed in at least $24 \%$ of 5-year-old children (O'Brien, 1994).

Erosion may be a consequence of either dietary factors such as citrus fruits, or of regurgitation such as occurs in bulimia. In young children it is most often thought to be a result of dietary factors (Smith \& Shaw, 1987). In particular, it is thought to be a consequence of drinks of low $\mathrm{pH}$, particularly fruit juices and carbonated drinks. Whilst carbonated drinks are thought not to be suitable for infants or young children, many drinks designed for use at the time of weaning are fruit juices or fruit-based. Results of more than one investigation have demonstrated the erosive potential of this type of drink (Grenby $e t$ al. 1990; Duggal et al. 1996).

In one recent study, titratable acidity was high and $\mathrm{pH}$ low in some herbal drinks designed for infants. The same drinks demonstrated an acidogenic potential close to that of $100 \mathrm{~g}$ sucrose/l solution (Duggal et al. 1996).

As with caries, the frequency with which drinks of low $\mathrm{pH}$ are given and their timing are important factors in determining whether erosion occurs. It has proved very difficult to measure erosion both for epidemiological surveys and for individual subjects. Erosive potential is not necessarily equivalent to $\mathrm{pH}$ or to titratable acidity alone and measurement of this factor may also prove to be complex. It is apparent from in vitro and in vivo work that the process may be modified by, for example, saliva but the nature and extent of buffering against erosion is not fully understood.

In spite of these uncertainties, current advice that drinks other than milk and water should form a minority of drinks, should be confined to mealtimes and should not be given at night would seem particularly relevant in the context of the high prevalence of erosion affecting young children.

\section{SPECIAL CONSIDERATIONS}

Three special considerations may be identified in relation to dental health and weaning: particular weaning practices, the use of soyabean-based infant formulas and the use of sugar-containing medicines.

It has already been pointed out that caries prevalence is higher in children of Asian origin. There is some evidence to suggest that at least two weaning practices may have contributed to this finding. First, the addition of sugar, rusk or other sweetening agent to milk given in feeding bottles carries particular cariogenic potential (Williams \& Hargreaves, 1990). This practice has been shown to be particularly prevalent in mothers of Asian origin and living in the North of England, as a means to encourage their child to drink larger amounts of milk. Second, and for the same purpose, mothers of Asian origin may well continue to give drinks from a bottle well after the recommended time to move on to drinking from a cup (Williams et al. 1989; Williams \& Sahota, 1990).

Recent evidence has shown that these traditional beliefs and practices may be difficult to alter. In a study in the same area, $54 \%$ of a group of Pakistani Muslim mothers said their 3 -year-old child still had a bottle and $35 \%$ that the child had a bottle at night, with no significant difference between mothers who had been born in the UK and those born in Pakistan (Godson \& Williams, 1996). In contrast, in the UK national nutrition survey $28 \%$ of 3-year-olds had a bottle and $19 \%$ had a bottle at night (Hinds \& Gregory, 1995).

Dietary restrictions at weaning may have a particular effect on dental health. For example, in buying manufactured infant and baby foods to use at weaning it has been suggested that mothers of Muslim families may rely particularly on such items as egg custards (with a high sugar content) since these are accepted to be Halal (Williams et al. 
1989; Williams \& Sahota, 1990). Families may be less confident about manufactured savoury or meat-based items at this time.

Soyabean-based formulas may be used in preference to conventional types. Because they contain sucrose rather than lactose, soyabean-based infant formulas may carry additional cariogenic risk. This suggestion has received media attention but clinical evidence has been difficult to find. Relatively few infants are given soyabean-based formulas (Mills \& Tyler, 1992), and results of one small recent study suggested their acidogenic potential to be little different from that of more conventional types of formula (Walton et al. 1995). However, acidogenic potential may not be the only indicator of cariogenicity. Until clearer evidence emerges it seems wise, therefore, to maintain current precautions, i.e. because of the potential risk, parents should be advised that good weaning practice is especially important for children given soyabean-based infant formulas (Department of Health, 1994).

Sugar-containing medicines for children form a particular risk factor. These are the ones most likely to be offered to infants, but they have been shown to be associated with higher levels of caries (Roberts \& Roberts, 1979; Duxbury et al. 1988). A wider range of sugar-free medicines is now available, but efforts are still needed to encourage routine use of these products when they are needed. This is true both for those sold over the counter and for prescription-only types of medicines.

\section{LABELLING}

For both nutritional and dental-health purposes it is important that mothers are encouraged to make appropriate choices of weaning foods and drinks for their child. It has been shown that some mothers try to avoid sugars in manufactured foods, but labelling conventions may have made this difficult in the past (Tyrell \& Rugg-Gunn, 1990a,b).

In some cases there has been little indication of sugar content in the nutritional information, in others sugars have been included with carbohydrate content. Some claims made may also have been confusing to mothers. For example, there has been movement by manufacturers towards removing 'added sugars' from commercial products for infants or babies (Durward, 1991). Whilst this represented an encouraging development it may produce little benefit for dental health if sugars are replaced with fruit juices or fruit concentrates or if a food is already high in naturally-occurring sugars. In simple terms, claims of 'no added sugars' may give little assurance of 'better for teeth' in the way parents might assume and may, therefore, be unhelpful to parents seeking to safeguard dental health.

Manufacturers of foods and drinks must respond to consumer pressure. Recently there has been a demand for 'natural' ingredients or in some cases, 'organic' products. From a dental health point of view, it may need to be emphasized that natural products such as honey carry as great a risk to dental health as more technically-named sweeteners.

The COMA working group addressed the problem of labelling. COMA (Department of Health, 1994) recommended that all weaning foods and drinks should carry consistent labelling that could be understood by parents and that included an indication of sugar content. This should apply to all baby and infant foods and drinks, irrespective of their derivation.

\section{FLUORIDES AT WEANING}

Fluorides have been well demonstrated to reduce dental caries. It is believed that fluorides may act both pre-eruptively and post-eruptively, but current philosophy is that post- 
eruptive effects may be the more important of the two. For all age-groups, water fluoridation remains the most effective way of using fluorides to prevent caries (Murray $e t$ al. 1991).

Where water fluoridation has not been introduced, greater reliance may need to be placed on fluoride supplements and fluoride toothpastes.

When they were first introduced, fluoride dietary supplements were seen as a substitute for water fluoridation. To be effective, supplements need to be given regularly for many years. Supplements have also been associated with an increased prevalence of enamel opacities, particularly when given inappropriately in areas with optimal water fluoride levels. As a consequence, supplements are no longer generally regarded as a public health measure. Recent recommendations are that they should be used only for children who are considered to be at high risk of caries and who live in areas with sub-optimal water fluoride levels (British Society of Paediatric Dentistry, 1996).

Fluoride toothpastes represent the most widespread use of fluoride. Although these are not necessary when toothbrushing begins, many mothers use them from the outset and, in some cases, will use toothpaste to clean a baby's mouth before teeth erupt. Toothpastes developed specifically for children are now available. These vary in their fluoride content, most containing between 400 and $1000 \mu \mathrm{g}$ fluoride/g. There is no doubt that fluoride toothpastes promote oral health and represent an important public health measure. However, the benefits they provide in preventing caries must be balanced against risks. Very young children cannot spit out effectively and particularly if relatively large amounts of pastes are used, there is a potential risk of a child ingesting too much fluoride.

If a mother wishes to use toothpaste for a young child it is recommended that only an amount the size of a small pea should be used and that a parent should supervise brushing up to at least the age of 6 years. Lower fluoride formulations may be more suitable for children at low risk of caries (British Society of Paediatric Dentistry, 1996). However, it must be said that as in the case of weaning foods and drinks, current labelling conventions may make this choice a difficult one for parents.

\section{CONCLUSIONS}

The COMA committee (Department of Health, 1994) has laid down a series of clear recommendations for weaning practices and a weaning diet that will help parents achieve good dental health for their children. It may be concluded from the report that those giving advice, as well as manufacturers and government all have a role to play in achieving this goal.

\section{REFERENCES}

British Society of Paediatric Dentistry (1996). A policy document on fluoride dietary supplements and fluoride toothpastes for children. International Journal of Paediatric Dentistry 6, 139-142.

Department of Health (1989). Dietary Sugars and Human Disease. Report on Health and Social Subjects no. 37. London: H.M. Stationery Office.

Department of Health (1994). Weaning and the Weaning Diet. Report on Health and Social Subjects no. 45. London: H.M. Stationery Office.

Downer, M. C. (1994). Caries prevalence in the United Kingdom. International Dental Journal 44, Suppl. 1, 365-370.

Duggal, M. S., Toumba, K. J., Pollard, M. A. \& Tahmassebi, J. F. (1996). The acidogenic potential of herbal baby drinks. British Dental Journal 180, 98-103.

Durward, L. (1991). Sugar in baby foods. Dental Update 18, 162-165.

Duxbury, A. J., Clark, C. M. \& Whittle, J. G. (1988). Sugar based medicines and dental caries. Medical Sciences Research 16, 243-244. 
Godson, J. H. \& Williams, S. A. (1996). Oral health and health related behaviours among three-year-old children born to first and second generation Pakistani mothers in Bradford, UK. Community Dental Health 13, $27-33$.

Gregory, J. R., Collins, D. L., Davies, P. S. W., Hughes, J. M. \& Clarke, P. C. (1995). National Diet and Nutrition Survey: Children Aged 1/2 to 4l/2 Years. vol. 1, Report of the Diet Survey. London: H.M. Stationery Office.

Grenby, T. H., Mistry, M. \& Desai, T. (1990). Potential dental effects of infants' fruit drinks studied in vitro. British Joumal of Nutrition 64, 273-283.

Health Education Authority (1996). The Scientific Basis of Dental Health Education. London: Health Education Authority.

Hinds, K. \& Gregory, J. R. (1995). National Diet and Nutrition Survey: Children Aged 11/2 to 41/2 years. vol.2, Report of the Dental Survey. London: H.M. Stationery Office.

Holt, R. D. (1990). Caries in the preschool child: British trends. Journal of Dentistry 18, 296-299.

Holt, R. D., Winter, G. B., Downer, M. C., Bellis, W. J. \& Hay, I. S. (1996). Caries in preschool children in Camden in 1993/94. British Dental Journal 181, 405-410.

King, J. M., Pitter, A. F. V. \& Edmunds, H. (1983). Some social predictors of caries experience. British Dental Journal 155, 266-268.

Kite, O. W., Shaw, J. H. \& Sognnaes, R. F. (1950). The prevention of experimental tooth decay by tube feeding. Journal of Nutrition 42, 89-103.

Lunt, R. C. \& Law, D. (1974a). A review of the chronology of calcification of deciduous teeth. Journal of the American Medical Association 89, 599-606.

Lunt, R. C. \& Law, D. (1974b). A review of the chronology of eruption of deciduous teeth. Journal of the American Medical Association 89, 872-879.

Mills, A. \& Tyler, H. (1992). Food and Nutrient Intakes of British Infants Aged 6-12 Months. London: H.M. Stationery Office.

Murray, J. J., Rugg-Gunn, A. J. \& Jenkins, G. N. (1991). Fluorides in Caries Prevention, 3rd ed. Oxford: Butterworth Heinemann.

Nunn, J., Shaw, L. \& Smith, A. (1996). Tooth wear - dental erosion. British Dental Journal 180, $349-352$.

O'Brien, M. (1994). Children's Dental Health in the United Kingdom 1993. London: H.M. Stationery Office.

Orland, F. J., Blaney, J. R., Harrison, R. W., Reyniers, J. A., Trexler, P. C., Wagner, M., Gordon, H. A. \& Luckey, T. D. (1954). Use of the germ-free animal technic in the study of experimental dental caries. Journal of Dental Research 33, 147-174.

Persson, L. A., Holm, A. K., Arvidsson, S. \& Samuelson, G. (1985). Infant feeding and dental caries - a longitudinal study of Swedish children. Swedish Dental Journal 9, 201-206.

Pitts, N. B. \& Palmer, J. D. (1994). The dental experience of 5-, 12- and 14-year old children in Great Britain. Surveys co-ordinated by the British Association for the Study of Community Dentistry in 1991/92, 1992/3 and 1990-91. Community Dental Health 11, 42-52.

Roberts, I. F. \& Roberts, G. J. (1979). Relation between medicines sweetened with sucrose and dental disease. British Medical Joumal ii, 14-16.

Rugg-Gunn, A. J. (1993). Dental caries - the role of dietary sugars. In Nutrition and Dental Health, pp. 113193. Oxford: Oxford University Press.

Silver, D. H. (1987). A longitudinal study of infant feeding practice, diet and caries related to social class in children aged 3 and 8-10 years. British Dental Journal 163, 296-300.

Smith, A. J. \& Shaw, L. (1987). Baby fruit juice and tooth erosion. British Dental Journal 167, $65-67$.

Tyrell, A. \& Rugg-Gunn, A. J. (1990a). The current status of nutrition labelling in the United Kingdom Community Dental Health 7, 351-357.

Tyrell, A. \& Rugg-Gunn, A. J. (1990b). A survey of nutrition labelling of sugar containing foods in the north of England in 1989. Community Dental Health 7, 359-367.

Walton, A. G., Moynihan, P. J. \& Wright, W. G. (1995). The effect of soya infant formula on the pH of dental plaque. Journal of Dental Research 74, 850Abstr.

Williams, S. A. \& Hargreaves, J. A. (1990). An inquiry into the effects of health related behaviour on dental health among young Asian children resident in a fluoridated city in Canada. Community Dental Health 7, 413420 .

Williams, S. A. \& Sahota, P. (1990). An inquiry into the attitudes of Muslim Asian mothers regarding infant feeding practices and dental health. Journal of Human Nutrition and Dietetics 3, 393-401.

Williams, S. A., Sahota, P. \& Fairpo, C. G. (1989). Infant feeding practices within white and Asian communities in inner-city Leeds. Journal of Human Nutrition and Dietetics 2, 235-238. 